\title{
Kant y Marx: heteronomía y alienación en la construcción de la libertad*
}

Fecha de entrega: 30 de octubre de 2018

Fecha de evaluación: 13 de diciembre de 2018

Fecha de aprobación: 29 de enero de 2019

Javier Gacharná Muñoz ${ }^{* *}$

\section{Resumen}

La tensión principal de la reflexión corre a cuenta del problema de la libertad en ambos autores. En Kant la búsqueda del principio supremo de la moralidad y su expresión en el imperativo obedece a la necesidad de la libertad de la voluntad. En Marx la voluntad y la conciencia son constitutivas del ser humano, y por tanto el concepto de alienación - heteronomía - representa tanto la crítica al capitalismo como la imperiosa necesidad de superarla.

Queremos recrear y enlazar dos ideales de humanidad, inspirarnos en ellos a efectos de contribuir a la crítica del mundo actual y proponer caminos para un mundo mejor.

Palabras clave: moralidad, voluntad, humanidad, economía política, sociedad capitalista, construcción.

* Este artículo se relaciona con los estudios que el autor ha adelantado en torno a la filosofía práctica de Kant a partir de la revisión de conceptos como libertad, Dios y alma, y su vinculo tácito con preocupaciones sobre la experiencia comunicativa social y política. Citar como Gacharná Muñoz, J. (2019). Kant y Marx: heteronomía y alienación en la construcción de la libertad. Cuadernos de Filosofía Latinoamericana, 40(120), 37-54. D0I: 10.15332/25005375/5379

* Doctor en filosofía de la Universidad de Barcelona (España). Título en Gestión Pública y Ciencia Política, estudios en filosofía. Docente, miembros del equipo académico de la Subdirección de Proyección Institucional de la Esap. Correo electronico: jgacharnam@gmail.com 


\section{Kant and Marx: heteronomy and alienation in the construction of freedom}

\section{Abstract}

The main tension of the reflection is at the expense of the problem of freedom in both authors. In Kant the search for the supreme principle of morality and its expression in the imperative obeys the need for freedom of the will. In Marx, will and conscience are constitutive of the human being, and therefore the concept of alienation - heteronomy - represents both the critique of capitalism and the imperative need to overcome it.

We want to recreate and interweave two ideals of humanity, be inspired by them in order to contribute to the critique of today's world and propose ways for a better world.

Keywords: Morality, will, humanity, political economy, capitalist society, building.

\section{Introducción}

El objetivo de este artículo es trazar un conjunto de caminos entre la Fundamentación de la metafísica de las costumbres de Kant y los Manuscritos económico-filosóficos de 1844 de Marx. Proponemos encontrar en el concepto negativo kantiano de heteronomía un antecedente del concepto, también negativo, de alienación en Marx. El vínculo lo hacemos en función tanto de la teoría crítica, que el primero inicia y el segundo lleva a su culmen, como de la concepción de humanidad sostenida en la libertad y en sus propuestas de reflexión y acción.

Comparar autores o épocas constituye un riesgo en cualquier disciplina, aun cuando se haga con autores de la misma tradición. Buscamos una analogía entre dos conceptos en el marco de la teoría crítica. No llegamos, y no lo pretendemos, a la comparación de los autores. 
Tomamos distancia de la asociación más frecuente entre Hegel y Marx porque es la evidente en la obra de este último, en donde el primero es el ídolo a vencer. Aquí solo somos unos buscadores de la filosofía.

\section{La teoría crítica: momento fundacional y cúspide}

La crítica en Kant es el esfuerzo de convertir la vieja metafísica en fundamentación epistemológica (en la primera Crítica) y ética (en la Fundamentación y en la segunda Crítica). Esfuerzo que se traduce en la delimitación de las fronteras hasta donde la razón humana puede llegar con legitimidad (Deleuze, 1997). Kant encuentra la razón enseñoreada en el marco del proyecto leibniziano-wolfiano ocupándose de los asuntos clásicos que la metafísica arrastraba desde el mundo medieval: Dios, alma y origen del universo. En este mismo camino, la crítica en términos éticos apunta a poner en evidencia la debilidad de los cimientos sobre los cuales se pretende construir el edificio ético y al mismo tiempo aportar unos que soporten la reflexión y la acción.

La crítica en Marx obedece a dos niveles del trabajo desarrollados de manera simultánea: por una parte, la situación de miseria en la que se vive en la sociedad capitalista, por otra, la "denuncia" de las teorías que pretenden dar cuenta de esa realidad como si se tratara de una situación "natural”. Marx encuentra que la economía política controla la escena de las explicaciones sistemáticas no solo sobre el mundo económico, sino sobre el funcionamiento de la sociedad, los diferentes actores y los papeles que deben cumplir que coinciden con los que cumplen. La ética en el proyecto de Marx está imbricada con las condiciones materiales sin las cuales no es posible la humanidad (Uña, 1977).

Una coincidencia entre los autores es su lucha en contra del dogmatismo. El camino de la crítica pasa por determinar el alcance de las capacidades cognoscitivas y éticas de los humanos. No todas las aspiraciones en esos dos ámbitos, por más bienintencionadas que sean, son legítimas.

Para los autores criticar es poner en evidencia el significado y el alcance tanto de la teoría como de las prácticas que se le aparejan en tanto explicación y propuesta de transformación. El Kant de la Fundamentación se enfrenta tanto al empirismo como al racionalismo, que no logran aportar un cimiento firme a la ética (Gutiérrez, 1978). Por su parte, Marx enfrenta la economía política clásica que 
pretende naturalizar las desigualdades y plantear como suficientes sus explicaciones de la realidad.

\section{Heteronomía y alienación: conceptos análogos en alcance, contundencia y propuesta de acción}

Los dos conceptos refieren a la determinación de la acción por un agente externo al sujeto, independientemente de las características de esa exterioridad. El actuar ha de surgir de móviles que cada uno seleccione en la conjugación de ser individual y ser genérico. No son aceptables ni la coacción ni el egoísmo.

Mientras Kant parte de la metafísica de su época y del sentido común (Timmermann, 2007) como posibles principios de la moralidad orientadores de la acción, Marx lo hace de la teoría de la economía política clásica. Al pasar por el filtro de la crítica, estos puntos de partida permitirán la construcción del camino hacia la libertad como propuesta de humanidad. Esas fuentes de teoría y práctica, según los autores, no explican el fundamento sobre el cual descansan. Marx nos dice: "La economía política no nos ofrece una explicación del fundamento sobre [el] que descansa[n] la división del trabajo y el capital y la del capital y la tierra” (1987, p. 595). Por su parte, en el prólogo de la Fundamentación Kant deja claro que está enfrentando al statu quo de la ética:

No se piense que lo que aquí pedimos sea algo de lo que tenemos ya en la propedéutica, que el célebre Wolff antepuso a su filosofía moral, a saber: esa que él llamó filosofía práctica universal. El camino que hemos de emprender es totalmente nuevo. (Kant, 2005, p. 4)

Estamos frente a una transformación profunda del planteamiento metodológico en ambos autores. Las teorías que están contrastando e intentando superar las ven atrapadas en una especie de descripción que se convierte en limitación de la libertad y de la comprensión del mundo. Son cómplices, para Marx; insuficientes teóricamente y desorientadoras prácticamente, para Kant.

Kant está buscando el principio supremo de la moralidad (Kerstein, 2004) y lucha con las fundamentaciones que sostienen el edificio ético sobre lo empírico o lo 
teológico. Al caracterizar el imperativo categórico en las postrimerías del tratado que nos ocupa, advierte de la dificultad que implicó la búsqueda de un principio como el alcanzado: "Aquí vemos a la filosofía colocada sobre un delicado criterio que debe ser firme, a pesar de no pender del cielo ni apoyarse sobre la tierra" (Kant, 2005, p. 60; véase Sedgwick, 2008). Los principios empíricos no pueden ser el fundamento en tanto harían que la voluntad oscilara continuamente en un mar infinito de fuentes contingentes, que es lo propio de la experiencia. Dentro de esta última aparece uno de los contrincantes fuertes de Kant, a saber, las inclinaciones, que no son sino una forma de la heteronomía que pone a la capacidad moral a depender de las sensaciones. Servirnos de las sensaciones como brújula moral es recurrir a máximas de muy corto alcance. Esto haría inviables la libertad y la convivencia.

Pero depender de principios teológicos no es menos grave:

Que el concepto teológico, que deriva la moralidad de una omniperfecta voluntad divina, no solo porque somos incapaces de intuir su perfección y únicamente podemos derivarla de nuestros conceptos [...], sino porque, si no hacemos esto (lo cual supondría un tosco círculo vicioso en la explicación), el concepto que nos queda de su voluntad a partir de las propiedades de la ambición y el afán de dominio, unidas a las temibles representaciones del poder y el afán de venganza, tendrían que constituir las bases de un sistema de las costumbres que sería justamente el opuesto al de la moralidad. (Kant, 2005, p. 92)

Queda claro que no podemos recurrir como fundamento de la moralidad a la creencia en una voluntad divina que lo presida todo pues esto dejaría a la humanidad sumida en la más oscura de las heteronomías. La divinidad representa un ideal derivado de puros conceptos, y por lo tanto, le podemos asignar cualquier contenido.

En la Fundamentación no podemos sostener la moralidad con seriedad a partir de unos cuantos ejemplos, así surjan de algún personaje moralmente emblemático de la humanidad, ni tampoco de Dios, ya que ambos escenarios conducen a la dispersión, a la falta de firmeza en la construcción del principio, es decir, a la heteronomía.

Por su parte Marx está ajustando cuentas con la economía política y con la sociedad en la que impera la producción capitalista. En ese ajuste de cuentas pone en evidencia las limitaciones de la economía política clásica. El trayecto lo llevará a continuar su 
obra hasta llegar a la más grande de todas, que lleva por subtítulo Crítica de la economía política clásica. Para esta la forma en que se produce y distribuye la riqueza en la sociedad capitalista es un supuesto irrevisable.

Luego de la descripción de la forma de producir del capitalismo, que Marx asume para poner en evidencia las contradicciones de aquel, se concluye que pase lo que pase en la economía el trabajador estará mal. Dice Marx: “Así, cuando la sociedad decae, miseria progresiva del obrero, cuando progresa, miseria complicada, y cuando llega a su apogeo, miseria estacionaria” (1987, p. 563).

La economía política, al igual que la economía oficial actual, no ve humanidad en el trabajador, sino una bestia de trabajo, o lo que es lo mismo, recurso humano o talento humano o colaboradores.

En este camino hacia la alienación el anverso de la condición del trabajador lo representa el capital. La relación de sometimiento y dependencia del obrero respecto al dueño de los medios de producción no es marginal o secundaria en la producción capitalista, al contrario, es su esencia. Esto adelanta una conclusión, a saber, ningún cambio en la forma de producción o en el mejoramiento del salario aumenta la dignidad del que tiene que vender su capacidad de trabajo para subsistir. Las reformas, en la época de Marx y ahora, son distracciones para mostrar un capitalismo humano, cosa que es una contradicción en los términos.

La actitud despiadada del capital no es ocultada por la concepción que está criticando Marx:

Ricardo en su obra [Principios de economía política y tributación]: las naciones son solamente talleres de producción, el hombre es una máquina de consumir y producir; la vida humana un capital; las leyes económicas gobiernan ciegamente el mundo. Para Ricardo, los hombres no son nada, el producto lo es todo. (1987, p. 581)

Los Manuscritos muestran un amplio entramado conceptual antes de llegar a la alienación pues el camino teórico, metodológico y expositivo así lo requiere. Mostrar la situación del trabajador implica desvelar los engranajes que hacen posible el sometimiento, la alienación. Esta obedece a un conjunto de contradicciones que al mismo 
tiempo muestran la magnitud del problema - es un asunto estructural - e ilustran que el trabajo en el capitalismo no puede ser reivindicado.

De manera muy sintética podemos decir, con Marx, que la alienación es la pérdida de sí mismo (Marx, 1987). Para que funcione el concepto se requiere saber qué es ese sí mismo, qué es la humanidad, cuál es su esencia. De eso nos ocuparemos un poco más adelante.

Para seguir avanzando en el análisis de la alienación observemos a Marx describiendo los efectos de uno de sus aspectos:

La enajenación del trabajador en su objeto se expresa, con arreglo a las leyes de la economía política, de tal modo que cuanto más produce menos tiene que consumir, cuanto más valores crea más carente de valor, más indigno es él, cuanto mejor formado el producto, tanto más deforme el trabajador, cuanto más civilizado el objeto, tanto más bárbaro el que lo produce, cuanto más poderoso el trabajo más impotente el que lo realiza, cuanto más ingenioso el trabajo, más estúpido y más siervo de la naturaleza el trabajador. (1987, p. 597)

Este proceso se da de manera prototípica en el trabajo y la religión. Estas dos manifestaciones de la cultura son las fuentes por excelencia de la alienación. El trabajo, en cuanto actividad humanizante, pierde su carácter esencial al convertirse en una limitación del desarrollo de capacidades, de la imaginación y del disfrute. La religión tiene el mismo efecto de sometimiento y postración en cuanto impide que el ser humano sea el centro de sus realizaciones, el objetivo último de la construcción de civilización. La analogía termina cuando llega la posibilidad de superación del extrañamiento de la esencia: hay que cambiar las lógicas del trabajo, pero la religión simplemente la tenemos que superar, dejarla atrás.

La alienación tiene en los Manuscritos tres conjuntos de relaciones básicas que la determinan: el proceso productivo mismo, el resultado del trabajo y los otros seres humanos en cuanto individuos y en cuanto especie humana (Eagleton, 2015). Cada una de estas relaciones aporta al entramado de la enajenación. Más allá de la descripción que ensayábamos antes, la comprensión de la alienación ha de darse en el entramado que tensiona esos tres componentes (Renault, 2015). 
El trabajador se somete al trabajo porque no tiene otra alternativa. En el proceso productivo sus capacidades físicas y mentales se ven sometidas al lecho de Procusto del proceso productivo, sobre el cual él solamente puede determinar pequeñas cosas. La misma dinámica del trabajo aprovecha para darle mayor precisión al sometimiento (círculos de calidad, mejoramiento continuo, reingeniería).

El producto resultante, un bien o un servicio, adquiere más valor que quien trabaja y la única forma de adquirir un reconocimiento es por medio de los productos (mercancías). Esta es la inversión entre ser humano y cosas que Marx denuncia y que el desarrollo capitalista ha exacerbado. Finalmente, las relaciones entre seres humanos en lo inmediato y la universalización están atravesadas por las lógicas de la producción, que asumen la humanidad como recursos humanos.

Esto genera una inversión entre las funciones animales y las humanas en el humano. Los espacios y actividades en los cuales el trabajador se siente realizado quedan limitados a las funciones básicas que compartimos con otras especies. Las demás, las específicamente humanas como la imaginación, el goce de la naturaleza, el goce de lo bello, entre otras, quedan postergadas.

Esta limitación de las capacidades humanas se encuentra en la religión pues el desdoblamiento del creador en el proceso productivo y el sometimiento a su creación, este monstruo de Frankenstein del trabajo, es análogo en el fenómeno religioso:

Como en la religión, donde la propia actividad de la fantasía humana, del cerebro y el corazón humanos, obra como si se tratase de una actividad independiente del individuo, divina o diabólica, así también la actividad del obrero no es su propia actividad. Pertenece a otro, es la pérdida de sí mismo. (Marx, 1987, p. 598)

La alienación tiene una doble dimensión en el análisis de Marx (Renault, 2015). Por una parte, el esfuerzo por documentar las condiciones concretas en las que aparece, y por otra, el peso de la ideología que contribuye a sostener esas condiciones. No es suficiente el sometimiento material, físico del trabajador para mantenerlo produciendo y depauperarlo, sino que se requiere un conjunto de narraciones que le den legitimidad al proceso. El hombre, como fuerza física y creadora, es despojado en el trabajo y "lo mismo ocurre en la religión. Cuanto más pone el hombre en Dios, menos retiene para 
sí mismo. El obrero pone su vida en el objeto; pero ahora su vida no le pertenece a él sino al objeto" (Marx, 1987, p. 596).

En ese marco que acabamos de recorrer - a saber, con una moral soportada en principios empíricos, siempre cambiantes, o teológicos o en la cosificación del ser humano que queda reducido a mercancía - lo único que es posible es la heteronomía, el sometimiento de la voluntad humana a potencias que le son exteriores. Lo único que queda es la alienación.

\section{Concepción de humanidad}

La naturaleza humana, o el ser genérico o universal en el que están pensando los autores, se caracteriza por la libertad. Si esta no tiene cabida, la humanidad no se alcanza y estaríamos es una situación de ausencia de legitimidad ontológica. La presencia de la heteronomía y la alienación en los dos momentos de la Modernidad que los dos autores vivieron nos lleva a visualizar la magnitud de la crisis que cada uno aportó a la filosofía, la ética, la sociedad, en fin, la humanidad.

La preocupación de los autores por establecer principios sólidos en su posición moral y de lectura amplia de la sociedad surge del interés de aportar a la construcción de las condiciones que den cuenta de las concepciones de humanidad de la modernidad. En otras épocas la dignidad, el respeto, la centralidad de la especie humana no estaban presentes, y por consiguiente, exigencias al respecto estaban fuera de lugar.

Para los dos autores el humano en su centralidad se convierte en fundamento (Sánchez, 2003), en punto de partida para pensar y actuar colectivamente. La Fundamentación y los Manuscritos apuntan a que el ser humano en su vuelta analítica y práctica sobre sí, es punto de partida y de llegada de cualquier apuesta vital (Leopold, 2012). La diferencia es que Kant en este tratado permanece al nivel de la abstracción (cumpliendo su objetivo), mientras que Marx pone la abstracción en función de lo concreto.

Otra característica esencial del humano que encontramos en ambos autores es el uso de la razón que deviene conciencia. Tener la capacidad de saberse y determinarse por sí mismo haciendo parte de la colectividad en diferentes grados lleva a la autolegislación, al cálculo de los efectos de las acciones y la posibilidad de transformar el mundo. 
En este último aspecto la concepción de humanidad los lleva a su respectiva filosofía de la historia y la complementa. Se critica el presente en su despliegue de acontecer y también en la forma en que se piensa, al mismo tiempo que se proyecta la urgencia del cambio. La historia no está para ser narrada, sino para ser comprendida con la aspiración de modificarla en virtud del ideal de humanidad (Renault, 2015).

El ser humano tiene en ambos autores una doble condición: es parte de la naturaleza pero va más allá de esta (Eagleton, 2015):

El hombre es directamente un ser natural. Como ser natural y ser natural vivo, se halla dotado, en parte, de fuerzas naturales, de fuerzas vivas, es un ser natural activo; estas fuerzas existen en él como dotes y capacidades, como instintos; y en parte, es, en cuanto ser natural y corpóreo, dotado de sentidos, objetivo, un ser que padece, un ser condicionado y limitado, como lo son también el animal y la planta; esto quiere decir que los objetos de sus instintos existen fuera de él, como objetos independientes de él, pero son objetos de sus necesidades, indispensables para el ejercicio y afirmación de las fuerzas de su ser. (Marx, 1987, p. 653)

En esta cita encontramos la justificación de la propuesta marxista de partir de lo inmediato y en la abstracción mantener el contacto con lo material y proyectarlo al ideal (Ollman, 1973) ${ }^{1}$. Como lo veremos, la estructura es similar en Kant, aunque cambia la intención y el lugar de lo concreto.

Más adelante Marx muestra lo que considera la otra condición del ser humano:

Pero el hombre no es solamente un ser natural, sino que es, además, un ser natural humano; es decir, un ser que es para sí mismo y, por lo tanto, un ser genérico, y como tal debe necesariamente actuar y afirmarse tanto en su ser como en su saber. (1987, p. 654)

Diferentes posiciones filosóficas y religiosas anteriores a Marx podrían reivindicar la doble dimensión que estamos extrayendo de él. Sin embargo, ninguna había clamado

1 Ollman aporta una revisión de la dimensión natural del ser humano en Marx poniéndola en tensión con la concepción del sentido común. Aqui encontramos una analogía con la noción kantiana correspondiente: es punto de partida, pero para convertirse en criterio moral requiere del aporte filosófico. 
por un ser humano libre del sometimiento en el trabajo y de cualquier concepción que estuviese por encima de él.

Por su parte Kant pone en evidencia la misma dualidad antropológica, a la vez como referente negativo y camino hacia el deber ser:

Toda la filosofía moral descansa enteramente sobre su parte pura y, aplicada al hombre, no toma nada prestado del conocimiento relativo al mismo [sic] (antropología), sino que le otorga en cuanto ser racional leyes a priori; desde luego estas requieren todavía un discernimiento fortalecido por la experiencia, para discriminar por un lado en qué casos tienen aplicación dichas leyes y, por otro, procurarles acceso a la voluntad del hombre, así como firmeza para su ejecución. (Kant, 2005, p. 93)

Esa doble dimensión del ser humano - por una parte naturaleza que lo lleva a las inclinaciones y por otra, razón asociada con la capacidad para seguir normas autoimpuestas - lo convierte en el escenario de una lucha de la cual se ocupa la ética, tanto en el momento fundante de esta como en su aplicación.

Las dos dimensiones humanas se ven puestas en relación contradictoria y complementaria en las postrimerías de la Fundamentación cuando el avance en la búsqueda de la libertad está muy consolidado y problematizado:

Así pues, la razón ha de presuponer más bien que entre la libertad y la necesidad natural de las mismas acciones humanas no se hallará contradicción alguna, puesto que no puede renunciar al concepto de naturaleza ni mucho menos al de libertad. (Kant, 2005, p. 115).

Los problemas derivados de la construcción de la libertad, la cual al final del tratado no será satisfactoria para el autor, pasan justamente por la tensión naturaleza-razón, en la medida en que no podemos dejar de lado ninguna.

La tensión entre universalidad e individualidad es un aspecto central de la esencia de la humanidad que se pone en juego. Las dos concepciones de la acción logran construir una propuesta que hace del ser genérico o universal un complemento del portador de la acción, que inevitablemente es un ser particular. Marx no aceptaría la posición 
abstracta de Kant, como efectivamente rechaza las posiciones de Hegel y Feuerbach, y sin embargo la complementa para propiciar la emancipación. Por su parte, Kant encuentra muchos problemas en la metodología materialista, pero hace una apuesta por la acción partiendo del sentido común y elaborándolo filosóficamente para devolverle un sólido criterio (universal-particular) de acción moral.

Dignidad y humanidad se vuelven en ambos autores una y la misma cosa. No podemos hablar de humanidad sin que se cumplan ciertas condiciones que le asignen un valor intrínseco, específico, universal y particular al ser humano. Para Marx, en un pasaje de los Manuscritos (1987, p. 604), dignidad se equipara a humanidad y quedan muy lejos los asuntos técnicos como el salario, la mejora de las condiciones, el esfuerzo y el talento. Por su parte, Kant dedica una de sus formulaciones del imperativo categórico, que luego será la base de los derechos humanos a la dignidad. Dicha versión ha sido caracterizada como la formulación del fin en sí mismo y dice: "Obra de tal modo que uses a la humanidad, tanto en tu persona como en la persona de cualquier otro, siempre como un fin al mismo tiempo y nunca simplemente como un medio" (Kant, 2005, p. 66). Se evidencia que en ambos casos dignidad y finalidad de la humanidad están en el mismo orden que la concepción de humanidad.

La libertad es el punto de partida, camino y destino del ser humano. La gran búsqueda del mundo moderno es la universalización de la libertad. La disputa de los autores con la heteronomía y la alienación es la vía negativa de esa búsqueda. Podemos hacer confluir las entradas anteriores en la libertad. Si no se da esta como apuesta individual y colectiva, se desmorona cualquier ideal de humanidad y pierde legitimidad cualquier forma de organización social.

Los dos autores aquí abordados se toman en serio el giro copernicano y la perspectiva crítica poniendo en el centro al ser humano. A partir de ahí construyen un ideal de este en cuyo núcleo se encuentra la libertad.

\section{La propuesta de realización de la libertad como "superación" de la heteronomía y la alienación}

El horizonte es la realización de la libertad, pero para ello el primer y más difícil escollo es sobreponerse a la condición de heteronomía-alienación que hace parte de la 
vida del humano y ponerse en camino, individual y colectivo, hacia la humanización de la vida. ¿Cómo salir de la caverna en búsqueda del sol del bien, si precisamente estamos encadenados y asumimos como parte de nuestra naturaleza la alienación y la heteronomía? ¿Son suficientes la razón y la capacidad de comprender, propias del ser humano, para iniciar este camino?

Ante estas preguntas no tenemos una respuesta satisfactoria. Sin embargo, los autores sí apuestan por la realización de sus propuestas. El objetivo es común, pero sus métodos para alcanzarlo son diversos.

En el caso de Kant la profunda confianza en la razón (Baxley, 2010) conforma el telón de fondo para la superación de la heteronomía. Alejada de esa naturaleza instintiva en cuyo marco el esfuerzo ético es vano - pues el instinto tiene resuelta la representación, la interpretación y la acción - la humanidad tiene la posibilidad de convivir sensatamente. La radicalidad y pretensión de Kant está en poner a disposición de la humanidad un criterio tal que pueda resolver el camino de la reflexión ética a la acción, pasando por la individualidad universalizada y la intención.

Para Marx la transformación es inaplazable, es urgente, e inicia con la ruptura de la propiedad privada, que en algún momento del texto es puesta como fundamento, pero la relación se transforma en interdependencia con el resto del entramado conceptual. En este punto se pone en evidencia la concepción dialéctica del joven Marx (Renault, 2015).

Si preguntásemos a Kant cuál es la puerta para salir de la prisión de la heteronomía hacia la libertad, y por supuesto a una convivencia armónica, la respuesta es un entramado conceptual que incluye, por una parte, al pensador que aporta los criterios para orientar la conducta, y por otra, a la humanidad que asume el reto de guiarse por esa matriz abstracta (Malishev, 2014). Para Kant, si se llega a esta respuesta, estaríamos de nuevo en el nivel de las máximas, y ahí reina la heteronomía. El pensador aporta el principio supremo de la moralidad y su expresión en el abanico de los imperativos.

El carácter imperativo de la guía kantiana obedece a la necesidad que encuentra el autor de superar el carácter cambiante de las máximas, o lo que es lo mismo, la inconstancia del espíritu humano: hoy me orienta una máxima (piénsese en los dichos 
populares como sentencias previas o posteriores a los hechos), mañana otra y en cada caso tengo una justificación.

Las distintas versiones del imperativo obedecen a la estrategia kantiana de cerrar las posibles fugas hacia un criterio heterónomo o arbitrario. Lo que configuran esas tres entradas al mundo moralmente constituido es la confluencia entre el individuo y la humanidad. Dicho de otra manera, la superación de la heteronomía pasa por la conciencia de los otros en mí y de los efectos que mis acciones tienen en los demás. Este enunciado del imperativo encuentra eco en Marx cuando plantea la doble dimensión del ser humano: individual y genérico. Dimensiones que se separan por razones analíticas, pero están concebidas como unidad (Ollman, 1973).

Se complementa esta tensión entre autonomía-alteridad con el mencionado imperativo en su versión de la dignidad. La indicación kantiana, con claras resonancia en Marx, es que en la acción la humanidad, individual o universal, no puede ser solo medio, pero tampoco exclusivamente fin. Para Marx la dignidad es el anverso de las actuales condiciones de trabajo y no tiene lugar en el capitalismo. Ahí radica la diferencia con Kant pues en un régimen de propiedad privada sus implicaciones riñen con la dignidad. "La miseria nace, [...] de la naturaleza misma del trabajo actual" (Marx, 1987, p. 565). En este punto la propuesta de Marx es radical:

La superación positiva de la propiedad privada como apropiación de la vida humana es por ello la superación positiva de toda enajenación, esto es, la vuelta del hombre desde la religión, la familia, el Estado, etc., a su existencia humana, es decir, social. (Marx, 1987, p. 618; véase también Sánchez, 2003)

El tercer enunciado es el del reino de los fines. La indicación es obrar asumiéndose como legislador de un ideal denominado así. Un lugar hacia donde tiende la filosofía de la historia de los dos autores. ¿Cómo hacer posible la libertad en un marco regulado con criterio humanista? Manuel Garrido (2005), en su estudio preliminar de la Fundamentación, lo llama platonismo democrático y asegura que influyó en Marx ${ }^{2}$.

2 Garrido afirma: "Hay, salvando la abismal diferencia de principio, una innegable relación de influencia histórica y de analogía entre la dicotomía kantiana reino de la naturaleza / reino de los fines y la dicotomía marxiana reino de la necesidad/reino de la libertad" (2005, p. XX) 
El fin último, ese reino de los fines, se vuelve realización estética en el joven Marx. Es el despliegue del disfrute de los sentidos, del amor, de la voluntad. La realización futura del ideal de humanidad pasa por el afinamiento de la unidad de la doble condición humana. El ideal kantiano que jalona sin llegarse a cumplir es imperativo en Marx. Si eso que él ha definido (tan cerca de Kant) como lo propio del ser humano no hace parte de la vida cotidiana de todos, la sociedad pierde sentido. A partir de este planteamiento Marx pone en crisis a las ciencias que tantos progresos han mostrado. $\mathrm{Al}$ asumir estas su quehacer en términos de utilidad, abandonan tanto la esencia del hombre espiritual como la posibilidad de generar emancipación (Leopold, 2012) a partir del conocimiento acumulado.

Asimismo, como parte del proceso de superación de la alienación el ser humano tiene que dejar atrás la creencia de que debe su existencia a algo por encima de él (Marx, 1987, p. 625). En esta labor Marx le asigna a la ciencia un papel fundamental: aportar formas más elaboradas de representación del mundo, que no requieran hipótesis insostenibles o las fantasías de mundos paralelos.

\section{Reflexión final}

Tendríamos que insistir en todas las épocas, como parte de la herencia de Kant y Marx, en la transformación metodológica que pregunta por el fundamento y redunda en la legitimidad de los saberes y de la organización social misma. Hoy más que nunca son necesarias las dos versiones de la teoría crítica y su indagación por el fundamento. El imperativo es enfrentar el discurso mercenario que apoya irrestrictamente a un capitalismo cada vez más aplastante y efectivo.

Tanto en la abstracción fundante de la ética de Kant como en la revisión concreta de las condiciones del trabajo de Marx el mundo moderno es puesto en cuestión. Pues la idea de humanidad, la solidaridad, la centralidad del ser humano y la dignidad se vuelven enunciados vacíos frente a la crítica.

Tanto las lógicas del trabajo como las de lo religioso son formas básicas de la heteronomía y la alienación. Ambas pretenden mostrarse como espacio de libertad y son sometimiento, control y aplastamiento de la humanidad. La primera se podría superar con otras lógicas de producción, la segunda ha de desaparecer. No puede haber trabajo libre en este contexto ni concepción religiosa liberadora. Y no son las dos únicas 
formas de sometimiento, así que el imperativo es extender la crítica hacia la técnica, los medios de comunicación, el reformismo, la fragmentación de los derechos, los enfoques en ciencias sociales, la pequeña política (Coutinho, 2011), etc.

El único lugar donde es consistente la apología del trabajo capitalista es el anuncio a la entrada de los campos de concentración ("El trabajo os hará libres", Arbeit macht frei) ya que allí se muestra de manera clara y fluida la contradicción entre el sometimiento expreso e intencionado y el discurso libertario. Y un discurso como el religioso, que ofrece lotes en el más allá en medio de la miseria de la humanidad que prometió salvar es inhumano, cruel y cínico.

Los dos autores aquí revisados con su perspectiva crítica son destructores de los reformismos. Intentar una pequeña mejora de las condiciones morales o materiales no es más que una burla a la dignidad humana.

Destacamos la profunda confianza que Kant y Marx tienen en el progreso moral de la humanidad. Este progreso se desprende de la razón y la razonabilidad de los humanos. La primera hace referencia a la capacidad, a la facultad propia de todo humano, diría Kant; la segunda, a la posibilidad surgida de la capacidad de compartir una visión del mundo que se asume legítima y justa. Las filosofías de la historia que cada uno formula los llevan a proyectar la posibilidad de un futuro en el que las convicciones éticas se vuelvan relaciones humanas concretas y los ideales de humanidad se conviertan en creación libre.

La religión ocupa en los dos tratados un lugar negativo. Para Kant no es parte de la fundamentación de las costumbres pues conduce a la heteronomía; para Marx, es la forma de alienación por excelencia y no hay otro camino que dejarla atrás para que el ser humano sea tal (Sánchez, 2003; Eagleton, 2015).

Kant aporta una revolución filosófica muy profunda (giro copernicano, moral racional y libre). Por su parte, Marx apuesta por un nuevo nivel de concreción e introduce la transformación, el cambio de las condiciones materiales como parte innegociable de su propuesta. Estos dos giros se complementan, se necesitan como parte de un conjunto reflexivo práctico (en sentido kantiano y en sentido marxista) que conduzca al mejoramiento de la humanidad y de cada uno de sus miembros. 
Son muchas las contradicciones que nos dejan los autores. Baste mencionar, por el lado de Kant, el carácter de autoimposición del imperativo, que lo convierte en una forma de exterioridad que guía la acción. Planteado de otra manera, ¿cómo distinguir cuando la ley es verdaderamente autoimpuesta? Porque muchas de las manifestaciones de la heteronomía, como la religión, son asumidas en muchos casos de manera voluntaria. Por el lado de Marx, tendríamos que preguntar si la destrucción de la propiedad privada sería suficiente para dar por terminada la alienación.

Dos cosas llenan el ánimo de admiración y veneración siempre nuevas y crecientes, conforme mayor es la frecuencia y persistencia con que reflexionamos sobre ellas: el fantasma de la crítica que aún puede recorrer el mundo y la resistencia del pensar frente al autoritarismo.

\section{Referencias}

Baxley, A. M. (2010). Kant's theory of virtue: The value of autocracy. Cambridge: cuP.

Coutinho, C. N. (2011). La era neoliberal y la hegemonía de la pequeña política. Marx en el siglo xxi. En C. Diago, T. Moulian y P. Vidal (comps.), La vigencia del(os) marxismos(s) para comprender y superar el capitalismo actual (pp. 183-196). Santiago de Chile: Lom.

Deleuze, G (1997). Filosofía crítica de Kant. Madrid: Cátedra.

Eagleton, T. (2015). Por qué Marx tenía razón. ¿Y si todo lo que siempre se le ha recriminado fuera falso? Barcelona: Grup Editorial 62.

Garrido, M. (2005). Estudio preliminar. En I. Kant, Fundamentación de la metafísica de las costumbres (pp. VIII-XXv). Madrid: Tecnos.

Gutiérrez, C. (1978). La fundamentación de la ética de Kant y la peligrosidad de la terminología de los valores. Ideas y valores, 27(53-54), 187-195.

Kant, I. (2005). Fundamentación de la metafísica de las costumbres. Madrid: Alianza.

Kerstein, S. J. (2004). Kant's search for the supreme principle of morality. Cambridge: CUP. 
Leopold, D. (2012). El joven Marx. Filosofía alemana, política moderna y realización humana. Madrid: Akal.

Malishev, M. (2014). Kant: ética del imperativo categórico. La Colmena, 84, 9-21.

Marx, K. (1987). Escritos de juventud. México: FCE.

Ollman, B. (1973). Alienación. Marx y su concepción del hombre en la sociedad capitalista. Buenos Aires: Amorrortu.

Renault, E. (2015). Trabajo alienado y filosofía de la práctica (Manuscritos de 1844 y Tesis sobre Feuerbach). En G. Dumenil et al., Leer a Marx (pp. 146-183). Buenos Aires /Madrid: Amorrortu.

Sánchez, A. (2003). El joven Marx. Los Manuscritos de 1844. México: Ítaca.

Sedgwick, S. (2008). Kant's Groundwork of the metaphysics of morals: An introduction. Nueva York: cup.

Timmermann, J. (2007). Kant's Groundwork of the metaphysics of morals. Cambridge: CUP

Uña, A. (1977). ¿Existe una ética en Marx? Revista de Estudios Políticos, 213, 157-178. 